\title{
Synthesis of Normorphans through an Efficient Intramolecular Carbamoylation of Ketones
}

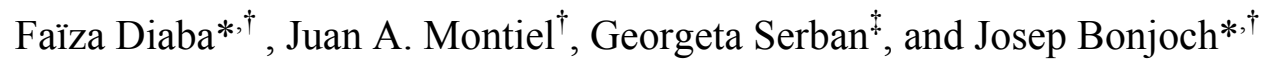 \\ ${ }^{\dagger}$ Laboratori de Química Orgànica, Facultat de Farmàcia, IBUB, Universitat de Barcelona, Av. Joan XXIII s/n, 08028- \\ Barcelona, Spain \\ \$Pharmaceutical Chemistry Department, Faculty of Medicine and Pharmacy, University of Oradea, Nicolae Jiaga 29, \\ 410028-Oradea, Romania
}

Supporting Information Placeholder<smiles>[R]C1CC2CCC(=O)C([R2])C2C1</smiles>

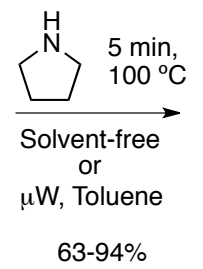<smiles>[R]C1C[C@H]2C[C@H](C1=O)N([R7])C2=O</smiles>

ABSTRACT: An unexpected C-C bond cleavage was observed in trichloroacetamide-tethered ketones under amine treatment and exploited to develop a new synthesis of normophans from 4-amidocyclohexanones. The reaction involves an unprecedented intramolecular haloform-type reaction of trichloroacetamides promoted by enamines (generated in situ from ketones) as counterreagents. The methodology was applied to the synthesis of compounds embodying the 6-azabicyclo[3.2.1] octane framework.

Methodologies involving the inter- or intramolecular formation of carbon-carbon bonds at the $\alpha$-position of ketones are important tools for the construction of molecular frameworks in organic synthesis. ${ }^{1}$ Nevertheless, to our knowledge, the $\alpha$-carbamoylation of ketones remains an "orphan" procedure. ${ }^{2,3}$ Whereas the feasibility of using intramolecular amide enolate alkylation (IAEA) in lactam synthesis is known, ${ }^{4}$ the umpolung version in which the amide carbonyl acts as an acceptor against an $\alpha$-carbonyl (ketone) group, such as a nucleophile, is unreported. The only procedures for the intramolecular C-carbamoylation described to date are carbamoyl radical, ${ }^{5}$ electrophilic, ${ }^{6}$ and $\mathrm{Ru}$-catalyzed ${ }^{7}$ cyclizations upon alkenes (Scheme 1).

\section{Scheme 1. Intramolecular Carbamoylation}

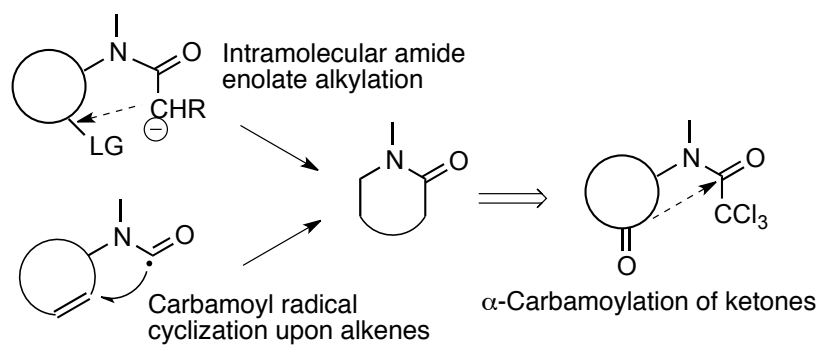

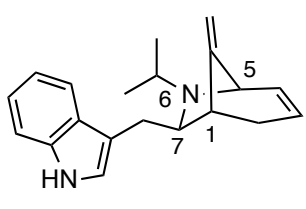

Peduncularine

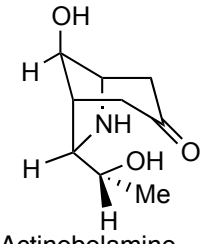

Actinobolamine

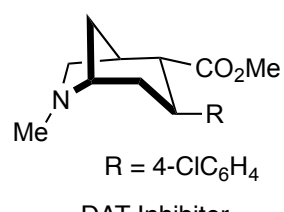

DAT Inhibitor
Figure 1. Normorphan Compounds

As part of our continuing interest in synthesizing lactams from trichloroacetamides, ${ }^{8}$ we report here an efficient method to synthesize the azabicyclic normorphan ring, based on an intramolecular carbamoylation of ketones. The 6-azabicyclo [3.2.1] octane (normorphan) nucleus is the backbone of peduncularine $^{9}$ and actinobolamine, ${ }^{10}$ and appears as a structural subunit in several other alkaloids. ${ }^{11}$ Additionally, various normorphans are pharmacologically interesting ${ }^{12}$ (Figure 1).

Among the vast array of synthetic procedures to achieve compounds embodying the 6-azabicyclo[3.2.1]octane skeleton, ${ }^{13,14}$ a scarcely used approach involves a ring-closing $\mathrm{C} 1$ C7 bond formation. Apart from our studies on the radical cyclization of $\alpha$-aminomethyl radicals, ${ }^{15}$ and those of Grainger using carbamoyl radicals, ${ }^{5,11}$ there are no other precedents for this disconnection in a synthetic plan toward the aforementioned bridged azabicyclic ring. 
Scheme 2. Enol Acetate vs Enamine Formation from Trichloroacetamide 1

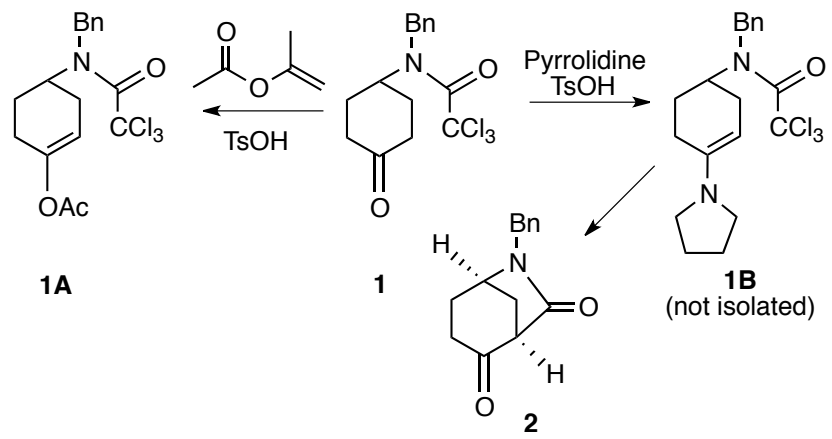

We began with the aim of extending our methodology for the radical cyclization of trichloroacetamides upon electronrich alkenes, previously reported using enol acetates (i.e. 1A) as radical acceptors, ${ }^{8 b}$ to the corresponding enamines, i.e. 1B (Scheme 2). During this study, it was serendipitously discovered that when ketone $\mathbf{1}^{\mathrm{8b}}$ was treated with pyrrolidine $(1.2$ equiv) and a catalytic amount of $\mathrm{TsOH}$ in toluene at reflux, normorphan 2 was isolated in $68 \%$ yield (Scheme 2) instead of the expected enamine of $\mathbf{1}$. After this surprising result, a synthetic study of the methodology toward 6azabicyclo[3.2.1] octanes using amine-promoted carbocyclization of trichloroacetamide-tethered ketones was undertaken.

Although organic reactions featuring trichloromethyl as a leaving group are well established (e.g., the haloform reaction), ${ }^{16}$ they have not been reported from trichloroacetamides using enamines as nucleophiles.

To improve the reaction conditions, microwave heating was explored in initial experiments to accelerate the process. At $120^{\circ} \mathrm{C}$, after only $15 \mathrm{~min}$, a full conversion was observed, but the target 2 was isolated in only a moderate yield (53\%, Table 1, Entry 1). No improvement was obtained by switching to acetonitrile as the solvent (Entry 2), but when the reaction was carried out in solvent-free mode without the $\mathrm{TsOH}$ catalyst and using conventional heating in a sealed tube, $\mathbf{2}$ was isolated in a better yield (78\%, Entry 3). Moreover, when a substoichiometric amount of pyrrolidine ( 0.5 equiv) was used, the yield improved further to reach $91-94 \%$ after only 5 min of reaction in a $1 \mathrm{~g}$-scale synthesis (Entry 4). Finally, it was found that the pyrrolidine loading can be diminished to $20-25 \%$ with little effect on the yield (Entry 5). Additionally, the process was also activated by the use of primary amines (e.g. benzylamine and allylamine), although large amounts were required and the yield was lower (Entries 7-8).

The new type of $\mathrm{C}-\mathrm{C}$ bond formation here described is probably based on a nucleophilic attack of an enamine generated in situ on a trichloroacetamide carbonyl group, with a concomitant release of the trichoromethyl anion as a leaving group. Indeed, a peak corresponding to $\mathrm{CHCl}_{3}$ was observed when recording the NMR spectrum of the crude reaction mixture in deuterated benzene.

The applicability of the methodology was subsequently explored on trichloroacetamides in which the benzyl group was replaced by primary or $\alpha$-branched alkyl groups (compounds 1b-1e). We tested two reaction conditions: the solventfree procedure under conventional heating (Method A), used in the $N$-benzyl series, and a microwave protocol with toluene as a solvent (Method B, Table 1, entries 9-15). When using compounds other than the $N$-benzyl derivative 1a, Method A afforded lower yields than Method B, which was attributed to the low homogeneity of the trichloroacetamide (1b-1e) and pyrrolidine mixture. The microwave procedure worked very well with trichloroacetamides bearing linear substituents at the nitrogen atom, while the yield decreased when the $\alpha$-position was branched (isopropyl or $\alpha$-methylbenzyl substituents, as in 1e and 3).

Table 1. Synthesis of Normorphans $2^{\mathrm{a}}$

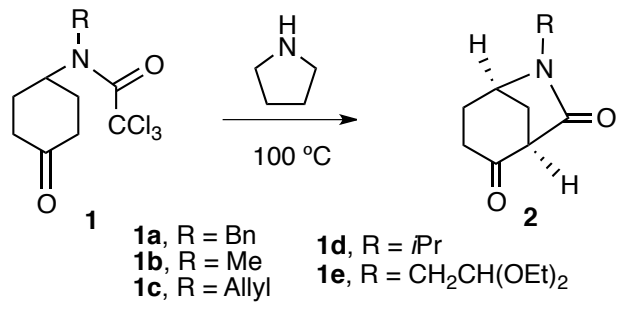

\begin{tabular}{|c|c|c|c|c|c|}
\hline entry & compd & $\operatorname{method}^{a}$ & $\begin{array}{l}\text { amine } \\
\text { (equiv) }\end{array}$ & $\begin{array}{l}\text { time } \\
(\mathrm{min})\end{array}$ & $\begin{array}{l}\text { yield } \\
(\%)^{b}\end{array}$ \\
\hline 1 & $1 \mathrm{a}$ & $\mathrm{B}^{c}$ & 1.2 & 15 & $53^{\mathrm{c}}$ \\
\hline 2 & $1 \mathrm{a}$ & $\mathrm{B}^{c}$ & 1.2 & 15 & $56^{\mathrm{c}}$ \\
\hline 3 & $1 \mathrm{a}$ & A & 1.2 & 15 & 78 \\
\hline 4 & $1 \mathrm{a}$ & A & 0.5 & 5 & $94^{\mathrm{d}}$ \\
\hline 5 & $1 \mathrm{a}$ & A & 0.25 & 5 & 80 \\
\hline 6 & $1 \mathrm{a}$ & B & 2 & 5 & 85 \\
\hline 7 & $1 \mathrm{a}$ & A & $1^{e}$ & 5 & 50 \\
\hline 8 & $1 \mathrm{a}$ & A & $5^{f}$ & 5 & $58^{\mathrm{g}}$ \\
\hline 9 & $1 b$ & A & 5 & 5 & $55^{h}$ \\
\hline 10 & $1 b$ & B & 2 & 5 & 96 \\
\hline 11 & $1 \mathrm{c}$ & A & 1 & 5 & 78 \\
\hline 12 & 1c & B & 2 & 5 & 82 \\
\hline 12 & $1 d$ & A & 5 & 10 & 50 \\
\hline 13 & 1d & B & 2 & 5 & 60 \\
\hline 14 & 1e & A & 1 & 5 & 71 \\
\hline 15 & $1 \mathrm{e}$ & $\mathrm{B}^{i}$ & 2 & 5 & 88 \\
\hline
\end{tabular}

${ }^{a}$ Unless otherwise noted, the reaction was carried out from 200 $\mathrm{mg}$ of $\mathbf{1 a}$ or from $100 \mathrm{mg}$ of $\mathbf{1 b}-\mathbf{1 e}$, using pyrrolidine as the amine. Method $A$ : The reaction was carried out from trichloroacetamide 1 at $100{ }^{\circ} \mathrm{C}$ in solvent-free mode. Method $B: \mu \mathrm{W}, 100{ }^{\circ} \mathrm{C}$ in toluene $(1 \mathrm{~mL}) .{ }^{b}$ Yields refer to pure compounds isolated by flash chromatography ${ }^{c}$ At $120{ }^{\circ} \mathrm{C}, \mu \mathrm{W}, p$-TsOH ( 0.06 equiv), and solvent $(2 \mathrm{~mL})$ : toluene or acetonitrile (entries 1 and 2$){ }^{d} 1 \mathrm{~g}$ scale. ${ }^{e}$ Benzylamine was used. ${ }^{f}$ Allylamine was used. ${ }^{g} 35 \%$ of 1 was recovered. ${ }^{h} 31 \%$ of 1 was recovered. ${ }^{i} 200 \mathrm{mg}$ scale.

The methodology was also applied to enantiopure trichloroacetamide 3 . Unlike 1, 3 required two equivalents of pyrrolidine and a prolonged reaction time to achieve a full conversion, leading to the diastereomers $\mathbf{4}$ and $\mathbf{5}$ in a 1:1.3 ratio and acceptable yield (Scheme 3 ). 
Scheme 3. Cyclization of Trichloroacetamide 3<smiles>C[C@H](c1ccccc1)N(C(=O)C(C)(Cl)C(C)(Cl)Cl)C1CCC(=O)CC1</smiles>

3<smiles>C[C@H](c1ccccc1)N1C(=O)[C@H]2C[C@H]1CCC2=O</smiles>

$4(26 \%)$

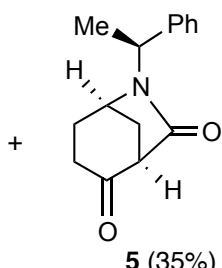

$5(35 \%)$
Evidence for the configuration of $4(1 S, 5 S)$ and $5(1 R, 5 R)$ was provided by NOESY experiments, which showed offdiagonal cross-peaks connecting $\mathrm{H}-4 \mathrm{eq}$ and $\mathrm{CH}_{3}$ in $\mathbf{4}$ and $\mathrm{H}-$ $4 \mathrm{eq}$ and aromatic protons in $\mathbf{5}$. This stereochemical elucidation agrees with the chemical shift of $\mathrm{H}-4 \mathrm{eq}$, which is shielded $(\delta$ 1.04 ) in 5 with regard to 4 ( $\delta 2.20)$, indicating that $\mathrm{H}-4 \mathrm{eq}$ is held below the benzene ring in $\mathbf{5}$ (see Supportin Information).

The two diastereomers 4 and $\mathbf{5}$ were submitted to $\mathrm{LiAlH}_{4}$ reduction to provide the corresponding amino alcohols $\mathbf{6}$ and 7, respectively (not shown, see SI), which after debenzylation gave enantiopure normorphan $\mathbf{8}$ and its enantiomer ent-8 (Scheme 4). We then used these new sterically demanding secondary amines (i.e. 8) ${ }^{17}$ to explore the asymmetric organocatalyzed synthesis of normorphan $\mathbf{2}$.

Scheme 4. Synthesis of enantiopure 8 and ent-8

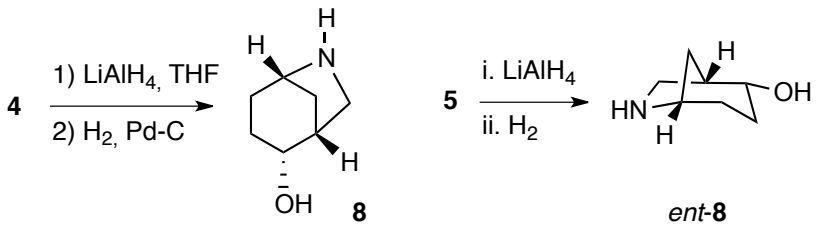

When trichloroacetamide $\mathbf{1}$ was treated with $\mathbf{8}$, the chemical yield of the carbamoylation was good (70\% yield), but the enantioselectivity was very poor $[(+)-2<20 \%$ ee). A short screening of organocatalysts gave disappointing results (see SI); although chemical yields ranged from good to excellent, the enantiomeric excess was again unsatisfactory, except for $(S)$-prolinamide. When the latter was used (0.5 equiv, DMSO, $\mathrm{rt}, 64 \mathrm{~h}$ ), the reaction afforded (-)-2 in 50\% yield and 63\% ee. These preliminary results are in line with previously noted difficulties in the organocatalyzed desymmetrization of 4aminocyclohexanones. 18,19

At this point, to examine the scope of the intramolecular carbamoylation reaction, the synthesis of more structurally complex normorphan compounds was undertaken (Scheme 5). When the $\alpha$-methyl-substituted cyclohexanone $9^{20}$ was treated with benzylamine to promote the carbamoylation of the ketone, the process took place regioselectively from the less substituted carbon, leading to the normorphan 10, which was also obtained after treating $\mathbf{9}$ with a secondary amine such as pyrrolidine (1.5 equiv, solvent-free, $73 \%$ ). Interestingly, an epimerization at $\mathrm{C} 3$ occurred in the basic reaction medium.

The reaction was extended to additional substrates, including the azaspiranic trichloroacetamide $\mathbf{1 1},{ }^{21}$ which led to the azatricyclic compound $\mathbf{1 2}$ as an epimeric mixture (2:1 ratio) in a good overall yield. This new heterocycle constitutes the ring core of the structurally unique pentacyclic alkaloid cephalocyclidin A. ${ }^{22}$ The structure of the major compound 12a was determined by X-ray crystallographic analysis (see SI).
Scheme 5. Synthesis of Other Normorphans

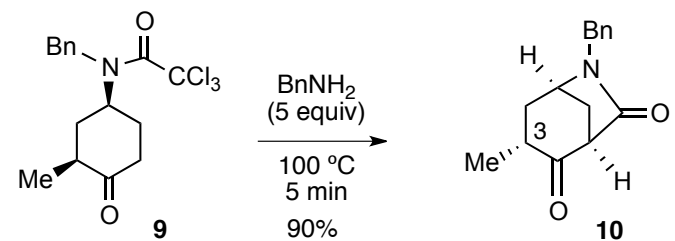<smiles>CC(=O)N(C)C1CN(C(=O)C(Cl)(Br)Br)C2(CCC(=O)CC2)C1</smiles>

11
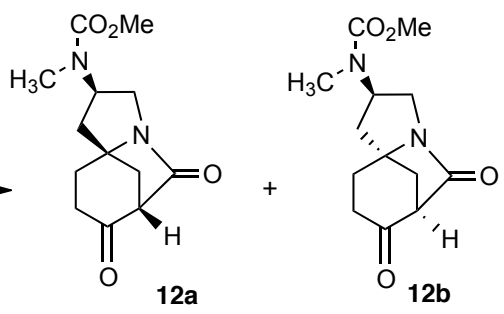

$(12 a / 12 b=2: 1)$
Additionally, we were interested in extending this reaction to achieve the six-membered ring scaffold from trichloroacetamide $\mathbf{1 3}^{23}$ (Scheme 6). However, the enlargement of the side chain bearing the trichloroacetamide moiety had a significant impact on the reaction course. Thus, treatment of $\mathbf{1 3}$ with pyrrolidine gave the anti-Bredt compound $14^{24}$ instead of lactam 13a. The structure of this unprecedented type of antiBredt ring (3-azabicyclo[[4.3.1]dec-5-ene) ${ }^{25}$ was elucidated by NMR data and secured by X-ray crystallographic analysis (Figure 2).

Scheme 6. Synthesis of anti-Bredt azabicyclo 14

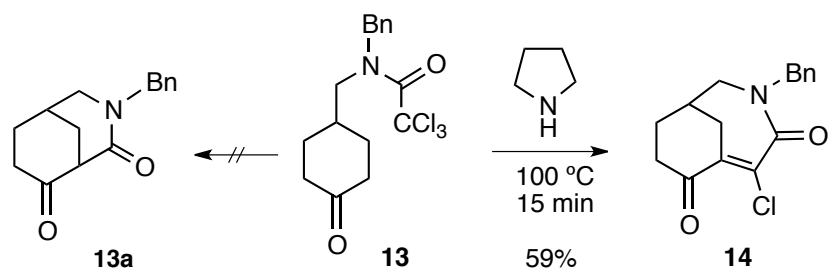

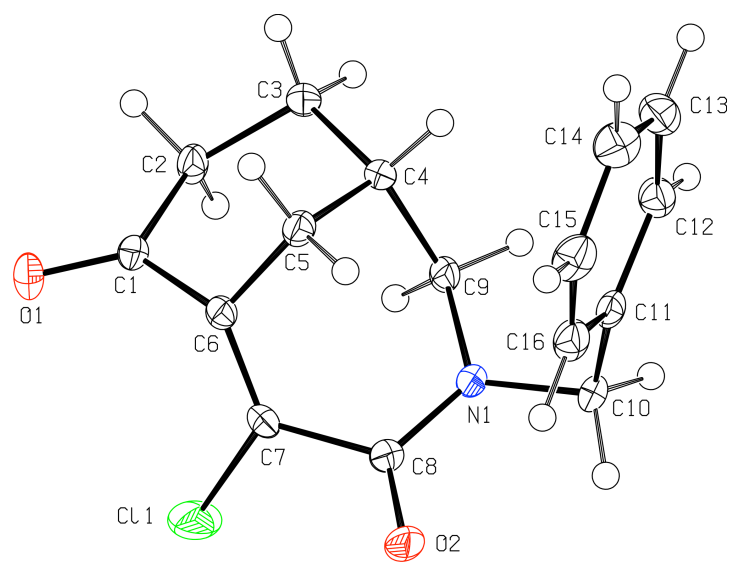

Figure 2. X-ray structure of 14

Not unexpectedly, trichloroacetate 15 behaved differently under pyrrolidine treatment, leading to the corresponding carbamate 16 (see ref 26). ${ }^{26}$ Thus, the presence of the nitrogen atom (i.e. the trichloroacetamide group) is essential for the accomplishment of the process since the oxygenated analog did not provide a cyclization product. 
In summary, a direct synthesis of the 6azabicyclo[3.2.1] octane ring, prevalent in a range of biologically active compounds, from an unprecedented $\alpha$ carbamoylation of ketones is reported. The process involves an intramolecular reaction of trichloroacetamides promoted by enamines (generated in situ from ketones) as counter-reagents. The lactam functionalization of this heterocycle promises several future applications, notably including the conversion of this building-block to the corresponding homo-derivative bearing a morphan nucleus. ${ }^{27}$

\section{ASSOCIATED CONTENT}

\section{Supporting Information}

Experimental procedures, spectroscopic and analytical data, NMR spectra of new compounds and X-ray data for 12a and 14 (CIF). This material is available free of charge via the Internet at http://pubs.acs.org.

\section{AUTHOR INFORMATION}

\section{Corresponding Author}

* E-mail: josep.bonjoch@ub.edu

* E-mail: faiza.diaba@ub.edu

\section{Notes}

The authors declare no competing financial interest.

\section{ACKNOWLEDGMENT}

Support for this research was provided by the Spanish MINECO (Project CTQ2013-41338-P).

\section{REFERENCES}

(1) (a) Stereoselective Synthesis of Drugs and Natural Products; Andrushko, V.; Andrushko, N. Eds.; Wiley-VCH: New York 2013; part 2.1, chapters 7-28. (b) Vander Wal, M. N.; Dilger, A. K.; MacMillan, D. W. C. Chem. Sci. 2013, 4, 3075-3079.

(2) (a) For a related transformation involving an intramolecular trapping of an isocyanate arising from a $\mathrm{N}$-monosubstituted trichloroacetamide, by a dienolate generated from an enone, see: Nishikawa, T.; Koide, Y.; Adachi, M.; Isobe, M. Bull. Chem. Soc. Jpn. 2010, 83, 66-68. (b) For an example of intermolecular carbamoylation of ketones using nitrourea under sonochemical PTC, see: Pazdera, P.; Simbera, J. Org. Prep. Proced. Int. 2011, 43, 297-301.

(3) For intermolecular C-carbamoylation processes not involving ketone compounds, see inter alia: (a) Lemoucheux, L.; Seitz, T.; Rouden, J.; Lasne, M.-C. Org. Lett. 2004, 6, 3703-3706. (b) Yasui, Y.; Tsuchida, S.; Miyabe, H.; Takemoto, Y. J. Org. Chem. 2007, 72, 5898-5900. (c) Yoshimitsu, T.; Matsuda, K.; Nagaoka, H.; Tsukamoto, K.; Tanaka, T. Org. Lett. 2007, 9, 5115-5118. (d) Kamijo, S.; Hoshikawa, T.; Inoue, M. Tetrahedron Lett. 2011, 52, 2885-2888. (e) Roy, S.; Roy, S.; Gribble, G. W. Tetrahedron 2012, 68, 9867-9923.

(4) Latif, M.; Yun, J. I.; Seshadri, K.; Kim, H. R.; Park, C. H.; Park, H.; Kim, H.; Lee, J. J. Org. Chem. 2015, 80, 3315-3520

(5) Grainger, R. S.; Welsh, E. Angew.Chem. Int. Ed. 2007, 46, 5377-5380. For carbamoylation of methoxybenzenes: (b) MillánOrtiz, A.; López-Valdez, G.; Cortez-Guzmán, F.; Miranda, L. D. Chem. Commun. 2015, 51, 8345-8348.

(6) (a) Yasui, Y.; Takemoto, Y. Chem. Record 2008, 8, 386-394. (b) Yasui, Y.; Kakinokihara, I.; Takeda, H.; Takemoto, Y. Synthesis 2009, 3989-3993.

(7) (a) Armarino, N.; Carreira, E. M. J. Am. Chem. Soc. 2013, 135, 6814-6817. (b) Li, B.; Park, Y.; Chang, S. J. Am. Chem. Soc. 2014, 136, 1125-1131.

(8) Using $\mathrm{Bu}_{3} \mathrm{SnH}$ or (TMS) ${ }_{3} \mathrm{SiH}$, see: (a) Quirante, J.; Escolano, C.; Merino, A.; Bonjoch, J. J. Org. Chem. 1998, 63, 968-976. (b) Quirante, J.; Escolano, C.; Diaba, F.; Bonjoch, J. J. Chem. Soc. Perkin
1, 1999, 1157-1162. (c) Diaba, F.; Pujol-Grau, C.; Martínez-Laporta, A.; Fernández, I.; Bonjoch, J. Org. Lett. 2015, 17, 568-571. Using Cu(I)/AIBN, see: (d) Diaba, F.; Martínez-Laporta, A.; Bonjoch, J.; Pereira, A.; Muñoz-Molina, J. M.; Pérez, P. J.; Belderrain, T. R. Chem. Commun. 2012, 48, 8799-8801. Using Grubbs' catalyst, see: (e) Diaba, F.; Martínez-Laporta, A.; Bonjoch, J. J. Org. Chem. 2014, 79, 9365-9372.

(9) (a) Roberson, C. W.; Woerpel, K. A. J. Am. Chem. Soc. 2002, 124, 11342-11348. (b) Hodgson, D. M.; Shelton, R. E.; Moss, T. A.; Dekhane, M. Org. Lett. 2010, 12, 2834-2837 and references therein.

(10) Holmes, A. B.; Kee, A.; Ladduwahetty, T.; Smith, D. F. J. Chem. Soc. Chem. Commun. 1990, 1412-1414.

(11) Betou, M.; Male, L.; Steed, J. W.; Grainger, R. S. Chem. Eur. $J$. 2014, 20, 6505-6517 and references therein.

(12) For normorphans as dopamine transporter inhibitors, see: Quirante, J.; Vila, X.; Bonjoch, J. Kozikowski, A. P.; Johnson, K. M. Bioorg. Med. Chem. 2004, 12, 1383-1391.

(13) For classical approaches, see: Bonjoch, J.; Mestre, E.; Cortés, R.; Granados, R.; Bosch, J. Tetrahedron 1983, 39, 1723-1728 and references therein.

(14) For some recent procedures, see: (a) Winkler, J. D.; Fitzgerald, M. E. Synlett. 2009, 562-564. (b) Campbell, C. L., Hassler, C.; Ko, S. S.; Voss, M. E.; Guaciaro, M. A.; Carter, P. H.; Cherney, R. J. J. Org. Chem. 2009, 74, 6368-6370. (c) Casavant, B. J.; Hosseini, A. S.; Chemler, S. R. Adv. Synth. Catal. 2014, 356, 2697-2702. (d) Liu, T.; Mei, T.-S.; Yu, J.-Q. J. Am. Chem. Soc. 2015, 137, 5871-5874.

(15) Quirante, J.; Vila, X.; Escolano, C.; Bonjoch, J. J. Org. Chem. 2002, 67, 2323-2328.

(16) For some examples on the leaving ability of $\mathrm{CX}_{3}$ groups, see: (a) Zucco, C.; Lima, C. F.; Rezende, M. C.; Vianna, J. F.; Nome, F. J. Org. Chem. 1987, 52, 5356; (b) Morimoto, H.; wiedemann, S. H.; Yamaguchi, A.; Harada, S.; Chen, Z.; Matsunaga, S.; Shibasaki, M. Angew. Chem. Int. Ed. 2006, 45, 3146-3150. (c) Gerfaud, T.; Wei, H.L.; Neuville, L.; Zhu, J. Org. Lett. 2011, 13, 6172-6175. (d) Zhu, C.; Wei, W.; Du, P.; Wan, X. Tetrahedron 2014, 70, 9615-9620.

(17) For the use of normorphans as organocatalysts, see: List, B.; Coric, I.; Grygorenko, O.; Kaib, P. S. J.; Komarov, I.; Lee, A.; Leutzch, M.; Pan, S. C.; Tymtsunik, A. V.; van Gemmere, M. Angew. Chem. Int. Ed. 2014, 53, 282-285.

(18) Diaba, F., Bonjoch, J. Org. Biomol. Chem. 2009, 7, $2517-$ 2519.

(19) For a recent first example of very efficient organocatalytic desymmetrization of prochiral 4-aminocyclohexanones, see: Yamagata, A. D. G.; Datta, S.; Jackson, K. E.; Stegbauer, L.; Paton, R. S.; Dixon, D. J. Angew. Chem. Int. Ed. 2015, 54, 4899-4903.

(20) Racemic 9 was prepared in a six-step sequence (see Supporting Information).

(21) Diaba, F.; Martínez-Laporta, A.; Bonjoch, J. J. Org. Chem. 2014, 79, 9365-9372.

(22) Kobayashi, J.; Yoshinaga, M.; Yoshida, N.; Shiro, M.; Morita, H. J. Org. Chem. 2002, 67, 2283-2286.

(23) Vila, X.; Quirante, J.; Paloma, L.; Bonjoch, J. Tetrahedron Lett. 2004, 45, 4661-4664.

(24) For natural products with bridgehead double bonds, see: Mak, J. Y. W.; Pouwer, R. H.; Williams, C. M. Angew. Chem. Int. Ed. 2014, 53, 13664-13688.

(25) For synthetic approaches to 3-azabicyclo[4.3.1]decanes, see: (a) Hall Jr., H. K. J. Org. Chem. 1963, 28, 3213-3214. (b) Orvieto, F.; Botta, M.; Corelli, F.; Harper, S. Synth. Commun. 1999, 29, 36353649.

(26)
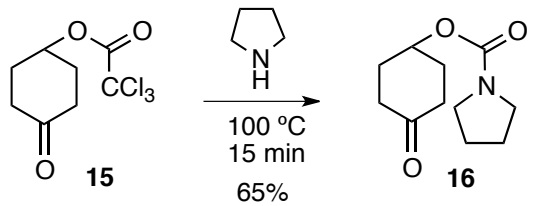

(27) For classical examples of the normorphan transformation to morphan compounds, see: (a) Legseir, B.; Henin, J.; Massiot, G.; 
Vercauteren, J. Tetrahedron Lett. 1987, 28, 3573-3576. (b) Nkiliza, J.;

Vercauteren, J.; Léger, J.-M. Tetrahedron Lett.1991, 32, 1787-1790. 